\title{
Differential responses of exogenous melatonin on growth, photosynthesis and antioxidant defence system in two Brassica napus L.cultivars under chromium stress
}

\author{
Ahsan Ayyaz ${ }^{1, *}$, Muhammad Ahsan Farooq ${ }^{1}$, Aneela Kanwal ${ }^{2}$, Muhammad \\ Aslam $^{2}$, Muhammad Iqbal ${ }^{3}$, Azra Manzoor ${ }^{2}$, Ayesha Khalid ${ }^{2}$, Sarah Umer ${ }^{2}$, \\ Hussen Bano ${ }^{2}$, Sameen ${ }^{2}$, Basharat Rasool ${ }^{2}$, Habib-ur-Rehman Athar ${ }^{2}$, Zafarullah \\ Zafar $^{2}$
}

${ }^{1}$ Institute of Crop Science and Zhejiang Key Laboratory of Crop Germplasm, Zhejiang University, Hangzhou 310058, China ${ }^{2}$ Institute of Pure and Applied Biology, Bahauddin Zakariya University, Multan 60800, Pakistan.

${ }^{3}$ University of Okara, 2 KM Multan Road Renala Khurd By Pass, Okara-Pakistan

Corresponding author: Ahsan Ayyaz

Abstract - Rapid industrialization throughout the world during last few decades causing high chromium resulted widespread of agricultural soil contamination. The increased chromium contents beyond permissible level in some agricultural land areas increasing widespread concern about food safety. This study was carried out for evaluation of metal toxicity damage and its possible mitigation and improved photosynthetic efficiency by melatonin treatment in canola plants exposed to four melatonin levels $(0,1,5,10 \mu \mathrm{M})$ treated with chromium stress $(0,50,100 \mu \mathrm{M})$ for two days. Chlorophyll fluorescence a transients considered one of the best tool for photosynthetic (photosystem II) efficiency analysis of two canola cultivars Ac-Excel and DGL with or without melatonin treatment against chromium stress analyzed by using OJIP test (at different time scale) chromium treated and non-treated plants. Enhanced ROS scavenging antioxidants enzymes (SOD, POD, APX,CAT) and $\mathrm{H}_{2} \mathrm{O}_{2}$, MD Aactivity photo synthetic efficiency was observed against chromium stress. DGL cultivar showed greatly affected and showed maximum reduction in performing index of photosystem II and yield for primary photochemistry as compared to chromium treated and non-treated plants as compared to Ac-Excel. Performing index primarily comprises of active number of reaction centers as per absorption, primary photochemistry yield and efficiency of electron transfer in electron transport chain activities were observed high in Ac-Excel cultivar. However exogenous application of melatonin protected the oxygen evolving complex of PSII and helped out in maintaining PSII activity. Thus OJIP fluorescence transients are quite helpful for understanding the intersystem electron transport beyond photosystem II response of canola cultivars in chromium stress.

Findings: Exogenous application of Melatonin can improve plant growth and development in heavy metal stress by modulation of photosynthesis in terms of enhanced photosystem II efficiency and redox potential in certain environmental stress conditions.

Keywords-OJIP, Chlorophyll fluorescence, Melatonin, chromium stress, Canola. 


\section{INTRODUCTION}

Heavy metals are naturally occurring trace elements of soil major source of agricultural soil contamination and major threat to food safety in several parts of the world (Ifon et al., 2019). Mostly, metals are found in soils as in the form of insoluble compounds such as oxides or carbonates, metallic complexes and free metallic ions. Among all heavy metals chromium is one of the toxic heavy metal causing severe threat to food security for many developing countries including Pakistan. Excessive use of fertilizers and pesticides, leather tanning, mining, natural disasters including volcanic eruption and weathering of rocks causing high level of chromium contents in agricultural soils (Kotecha et al., 2019). It has been found that chromium affects the physiological processes of plants mainly stunted growth, chlorosis and wilting of leaves, photosynthesis and roots damage, reduction in nutrients uptake ultimately causes death (Aparicio et al., 2019). Plants facing environmental abiotic stress conditions stimulates the formation of reactive oxygen species (ROS) which harms the production of biomolecules including nucleic acids, proteins and lipids, disturbing the sugars metabolisms and mitochondrial respiration of cell.

It has been reported that plants exposed to metal toxicity induces lipid peroxidation, which consequences membrane structure damage, enzymatic and transport activities. However, plant in response activates selfprotection mechanism such as cellular enzymatic antioxidants which scavenges reactive oxygen (ROS) and reduces the oxidative stress (Rajendran et al., 2019). The hyperactivity of antioxidants enzymes and their subcellular accumulation in different parts of plants against chromium, zinc, aluminum and copper have been reported in several studies (Ghori et al., 2019). Moreover, it was observed that chromium induced toxicity leads to the poor lamellar system development, fewer grana and enhanced thylakoid lumen ultimately consequences some ultrastructure changes in plant cell (Ali et al., 2013). These changes in ultrastructure of chloroplast might have some negative impact on energy transfer imbalance and photosynthesis.

Furthermore, chromium and other trace elements may cause ultrastructure abnormalities in mesophyll cells and root cells ultimately increased metal deposition in some plant parts. Several previous studies have suggested the inhibitory effect of chromium on PSII activity mostly studies have been performed on cellular membrane damaging effect, to increase knowledge about the negative effect of chromium on photosynthesis PSII activity to evaluate the toxic effect of chromium on photosynthetic apparatus (Souri et al., 2019), Chromium stress induces changes in ultrastructure of chloroplast, electron transport chain (Chen et al., 2019). At PSII chromium ions replaces the co-factor $\mathrm{Ca}^{2+}$ known to be very important for water-splitting, hence alters the structure and function of oxygen evolving complex. In addition to oxygen evolving complex chromium ions interacts with many essential electron acceptor proteins i.e $\mathrm{Q}_{\text {в }}$ foundin electron transport of PSII (Oves et al., 2016; Küpper et al., 2019).

Primarily melatonin is considered as an antioxidant because of its great potential to control the reactive oxygen species under a-biotic stresses including heavy metal toxicity, salinity, drought, cold and heat stress, ozone stress, chemical pollutants, herbicides and ultraviolet radiations makes it most interesting bio-stimulating molecule for agricultural crops (Kabiri, R. et al., 2018).Several studies have indicated the potential role of melatonin in alleviation of heavy metal stress, salt stress, drought stress, heat stress in many plant species (Wang, L.Y et al., 2015). Melatonin closely associated with reactive oxygen species (ROS) generation and cell signaling under certain environmental stress conditions, thus chloroplast considered the major site of melatonin production (Martinez, $\mathrm{V}$ et al., 2018).

Canola (Brassica napus L.)is well known and major source of edible oil throughout the world. Brassica species are considered as potential candidate against heavy metal stress because of its distinguishing characteristics such as heavy metal absorption, rapid growth and greater biomass (Meng et al., 2009). Canola plants have developed specific heavy metal tolerance mechanism that enables them to grow well in polluted soil. Thus, it is necessary to evaluate the Brassica species response or specific mechanism involved in metal tolerance. Hence, present study was carried out to analyze the Brassica napus tolerance against chromium stress by exogenously applied melatonin and its effects on plant growth, chlorophyll pigments, and enzymatic antioxidant system in alleviation of metal toxicity.

\section{METHODOLOGY}

Plant material and growth conditions present study was carried out to investigate efficiency of PSII in adverse effects of Chromium stress on the growth of Brassica napus L. var. AC-Excel and DGL. A pot experiment was performed in agricultural land of Bahauddin Zakariya University, 
Multan, Pakistan with normal environmental conditions $\left(30^{\circ} \mathrm{N}\right.$ and $\left.71^{\circ} 28 \mathrm{E}\right)$. Seeds of canola cultivars were obtained from Ayub Agriculture Research Institute (AARI) Faisalabad. River washed sand was used as a rooting medium. In experiment 120 plastic pots with diameter $28 \mathrm{~cm}$ with $8 \mathrm{~kg}$ sand were used, five to seven seeds were sown in each pot. After germination of the plants thinning was carried out leaving 4 equal distant plants in each pot. After twenty days of germination, plants were treated by various levels of $\mathrm{Cr}(0,50,100 \mu \mathrm{M})$ with Hoagland nutrient solution (full strength). After 10 days of chromium treatment foliar application of melatonin with different concentration $(0,1,5$, $10 \mu \mathrm{M})$ mentioned as MT0, MT1, MT2, MT3 were applied exogenously to the plants. Experiment was designed according to CRBD (completely randomized block design) with three $\mathrm{Cr}$ levels and four melatonin levels, two cultivars and five replicates for each treatment. After twenty days of treatment, plant fast chlorophyll a kinetic analysis was measured with Fluor Pen. After taking data of all parameters mentioned above, plants were harvested. Plants root and shoots were separated. Roots were washed out and plant fresh biomass (root and shoot) were measured. For dry biomass samples of plants (root and shoot) were dried in oven at $70{ }^{\circ} \mathrm{C}$ for 48 hours, then samples weight taken in grams (g) by digital electronic balance.

\section{Chlorophyll contents:}

For the estimation of chlorophyll contents of canola plants 0.2 gram leaf tissue was taken homogenized in $80 \%$ acetone in pestle and mortar. Extract after filtration was kept $10 \mathrm{ml}$ volume by adding $80 \%$ acetone in falcon tubes wrapped by aluminum foil to prevent chlorophyll degradation in light. Chlorophyll contents were measured at different wave lengths 663,652,645, and $470 \mathrm{~nm}$ by usingspectrophotometer (U-2900/2910 Hitachi).(Arnon, 1949).

\section{Analysis of O-J-I-P fast chlorophyll a transients}

Chlorophyll fluorescence data was recorded following nomenclature by (Kodru et al., 2015) and literature related to chlorophyll fluorescence available on its manufacturer website. For this fully matured third leaves of canola plants were selected, by using hand held device Fluor Pen FP 100fluorescence transients were observed by keeping plants in dark by using aluminum foil for 30 minutes.

\section{Antioxidants enzymes activity}

Fresh plants leaf tissue of 0.1 gram was homogenized in pre-chilled pistal and mortal with $1 \%(\mathrm{w} / \mathrm{v})$ polyvinyl poly pyrrolidone solution with $1.2 \mathrm{ml}$ of $50 \mathrm{mM}$ potassium phosphate buffer by maintaining $\mathrm{pH} 7.8$ along with adding $1 \mathrm{mM}$ EDTA-Na $\mathrm{N}_{2}$ and $0.3 \%$ Triton X-1000 solution.

APX enzyme activity was estimated by adding $1 \mathrm{mM}$ ascorbate solution to prepared solution, Extract was centrifuged at $13,000 \mathrm{rpm}$ for 20 minutes maintaining temperature at $4^{\circ} \mathrm{C}$ extract was used for following enzymes activities. SOD activity was measured according to (Zhang et al., 2013) methodology. Reaction mixture of $3 \mathrm{ml}$ including $13 \mathrm{mM}$ methionine, $75 \mathrm{mM}$ NBT, $2 \mathrm{mM}$ riboflavin, $0.1 \mathrm{mM}$ EDTA and $100 \mu \mathrm{L}$ enzyme extract along with $50 \mathrm{mM}$ sodium phosphate buffer ( $\mathrm{pH}$ 7.8).Reaction mixture was illuminated at light intensity of 90 for about $25 \mathrm{~min} \mu \mathrm{mol} / \mathrm{m}^{-2} \mathrm{~s}^{-1}$. SOD activity was observed by measuring the enzyme extract ability or activity ( $\mu \mathrm{mol} \mathrm{min}^{-1} \mathrm{~g}^{-1}$ ) of photochemical reduction of NBT (about 50\%) by using spectrophotometer

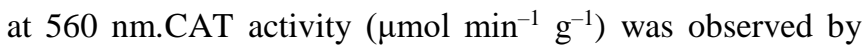
reduction in absorbance of reaction mixture at $240 \mathrm{~nm}$ by decomposition of $\mathrm{H}_{2} \mathrm{O}_{2}$ in $1 \mathrm{ml}$ of reaction mixture with $50 \mathrm{mM}$ sodium phosphate buffer ( $\mathrm{pH} 7.8$ ) in addition $10 \mathrm{mM}$ $\mathrm{H}_{2} \mathrm{O}_{2}, 20 \mu \mathrm{l}$ of enzyme extract according to (Aebi 1984).

POD activity ( $\mu$ mol $\min ^{-1} \mathrm{~g}^{-1}$ ) was observed by preparing $1 \mathrm{ml}$ reaction mixture with $100 \mathrm{mM}$ sodium phosphate buffer $(\mathrm{pH} 6.0) 16 \mathrm{mM}$ guaiacol solution $5 \mu \mathrm{l}$ of $10 \% \mathrm{H}_{2} \mathrm{O}_{2}$ (w/v) solution by following (Rao et al. 1996). APX activity $\left(\mu \mathrm{mol} \mathrm{min}^{-1} \mathrm{~g}^{-1}\right.$ ) was observed by reduction in absorbance at $290 \mathrm{~nm}$ as reduced ascorbate was oxidized in 1 $\mathrm{ml}$ of reaction mixture containing $50 \mathrm{mM}$ hepes- $\mathrm{KOH}$ of 7.6 $\mathrm{pH}$ with $0.1 \mathrm{mM}$ EDTA, $0.5 \mathrm{mM}$ ascorbate, $0.2 \mathrm{mM} \mathrm{H}_{2} \mathrm{O}_{2}$ and $20 \mu \mathrm{L}$ enzyme extract, reaction was started by the addition of $\mathrm{H}_{2} \mathrm{O}_{2}$ (Nakano and Asada 1981). Glutathione reductase activity was observed by following the methodology of (Griffith 1980). Fresh leaf tissue 0.1 gram were homogenized in pre-chilled pistil and mortars in $1.5 \mathrm{ml}$ of $5 \%$ sulfosalicylic acid and centrifuged at 12000 rom for 15 minutes then absorbance of supernatant was used at $412 \mathrm{~nm}$ for measurements.

\section{Estimation of MDA and $\mathrm{H}_{2} \mathrm{O}_{2}$}

$\mathrm{H}_{2} \mathrm{O}_{2}$ contents were measured by $5 \%$ trichloroacetic acid solution by following (Zhou et al., 2006). MDA were measured according to the method of (Hodges et al., 1999).

\section{Estimation of chromium $(\mathrm{Cr})$}

For the determination of chromium contents $0.1 \mathrm{~g}$ of dried leaf samples were taken in digestion flask with $2 \mathrm{ml}$ of digestion mixture was mixed and kept pre-night for about 12 
hours for complete digestion of leaf plant tissue in digestion mixture. After that flasks were heated on hotplate by gradually increasing the temperature from $50^{\circ} \mathrm{C}$ to $200^{\circ} \mathrm{C}$. By heating, color of plant samples turned black, at this stage about $0.5 \mathrm{ml}$ of $\mathrm{HClO}_{3}$ was added by using dropper. After this by increasing temperature plant samples become transparent. Then flasks were taken off from hotplate, cooled and diluted by adding $50 \mathrm{ml}$ of distil water. Then the calculation of chromium contents were performed by using atomic absorption spectrophotometer.

\section{RESULTS}

Chromium toxicity causes reduction $(\mathrm{P} \leq 0.001)$ in biomass (fresh and dry weight g/plant) (Fig.1) and Leaf number and quantum yield (Fig 2) of both the canola plants that of control plants. While melatonin treated plants showed improved plant growth in terms of fresh and dry biomass and leaf number in addition to quantum yield of both canola cultivars, especially at $5 \mu \mathrm{M}$ concentration melatonin treated Ac-Excel cultivar showed significant increase in plant height, leaf number and biomass as compared to DGL cultivar with and without chromium stress.
Overall chlorophyll contents were significantly affected by chromium stress $(\mathrm{P} \leq 0.001)$ including chlorophyll a, chlorophyll $\mathrm{b}$, chlorophyll $\mathrm{a} / \mathrm{b}$ and total chlorophyllof canola plants (Fig.3). While exogenous application of melatonin improved chlorophyll contents meanly 5 and $10 \mu \mathrm{M}$ concentration significantly increased chlorophyll contents in chromium treated and non-treated plants. Significant increase in plant height, biomass and chlorophyll contents in Ac-Excel shows more resistance as compared to DGL in chromium stress.

Whereas plants antioxidants activity was observed to be significantly higher $(\mathrm{P} \leq 0.001)$ under chromium stress as compared to control plants in both melatonin treated and non-treated canola plants. Chromium toxicity leads to enhance the total soluble proteins contents and reactive oxygen species $\mathrm{H}_{2} \mathrm{O}_{2}$ and MDA (Fig 4) consequently more production of ROS scavenging enzymes such as superoxide dismutase (SOD), Peroxidase (POD) and Catalase (CAT) to minimizechromium toxicity (Fig 5), additionally canola plants showedhigh APX (Ascorbate peroxidase) and Glutathione reductase enzyme activity (Fig 5) to scavenge/lower $\mathrm{H}_{2} \mathrm{O}_{2}$ or oxidative stress due chromium stress. 


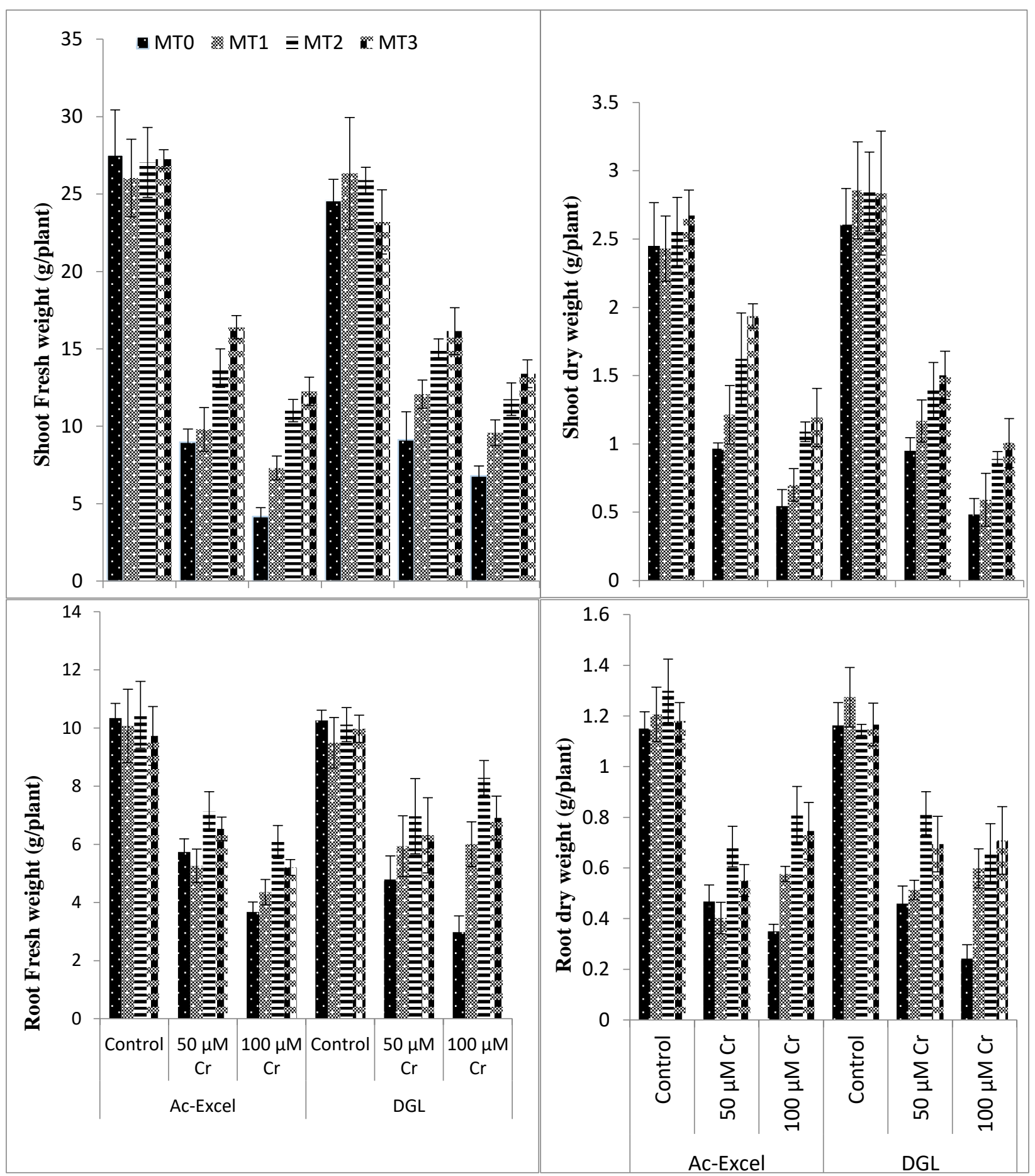

Fig.1: Melatonin induced Biomass changes of two Canola plants treated with chromium stress for two weeks. 

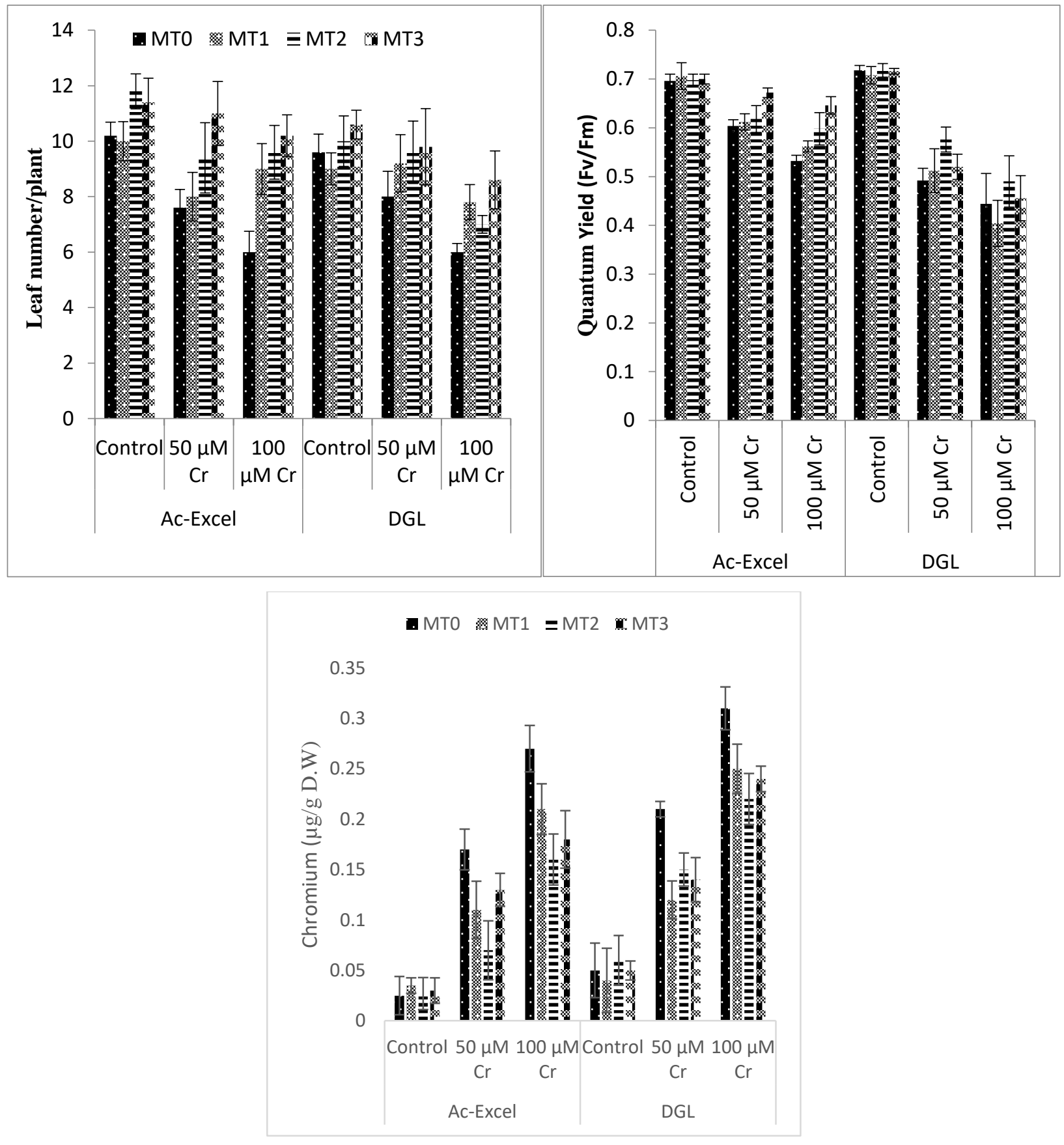

Fig.2:Melatonin induced Leaf Number/plant, Quantum yield and Chromium contents of two Canola plants treated with chromium stress for two weeks. 
International Journal of Environment, Agriculture and Biotechnology, 5(2)

Mar-Apr, 2020 / Available: https://ijeab.com/

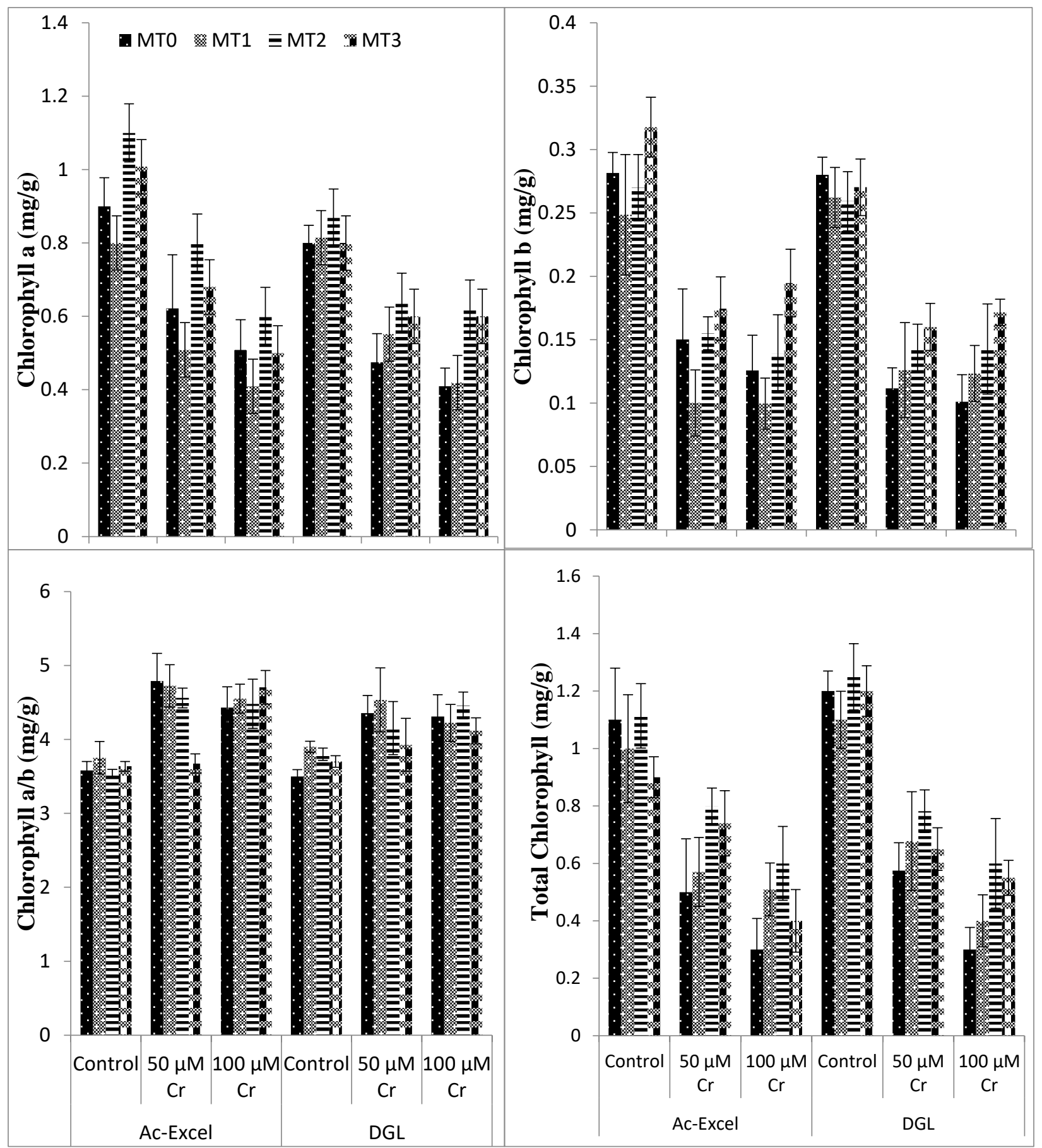

Fig.3: Melatonin induced Chlorophyll contents $(\mathrm{mg} / \mathrm{g})$ of two Canola plants treated with chromium stress for two weeks. 


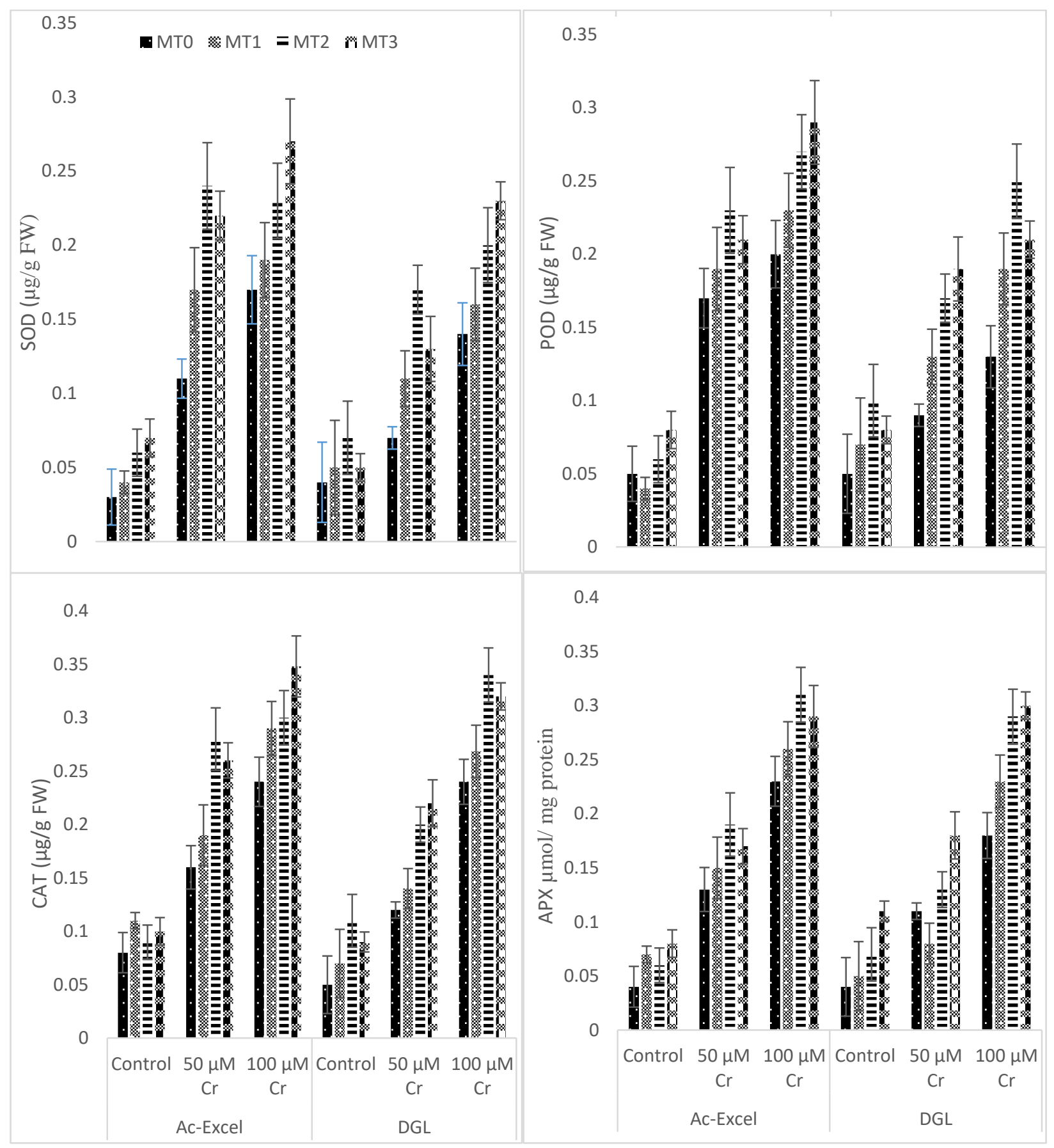

Fig.4: Melatonin induced SOD, POD, CAT, APX of two Canola plants treated with chromium stress for two weeks. 


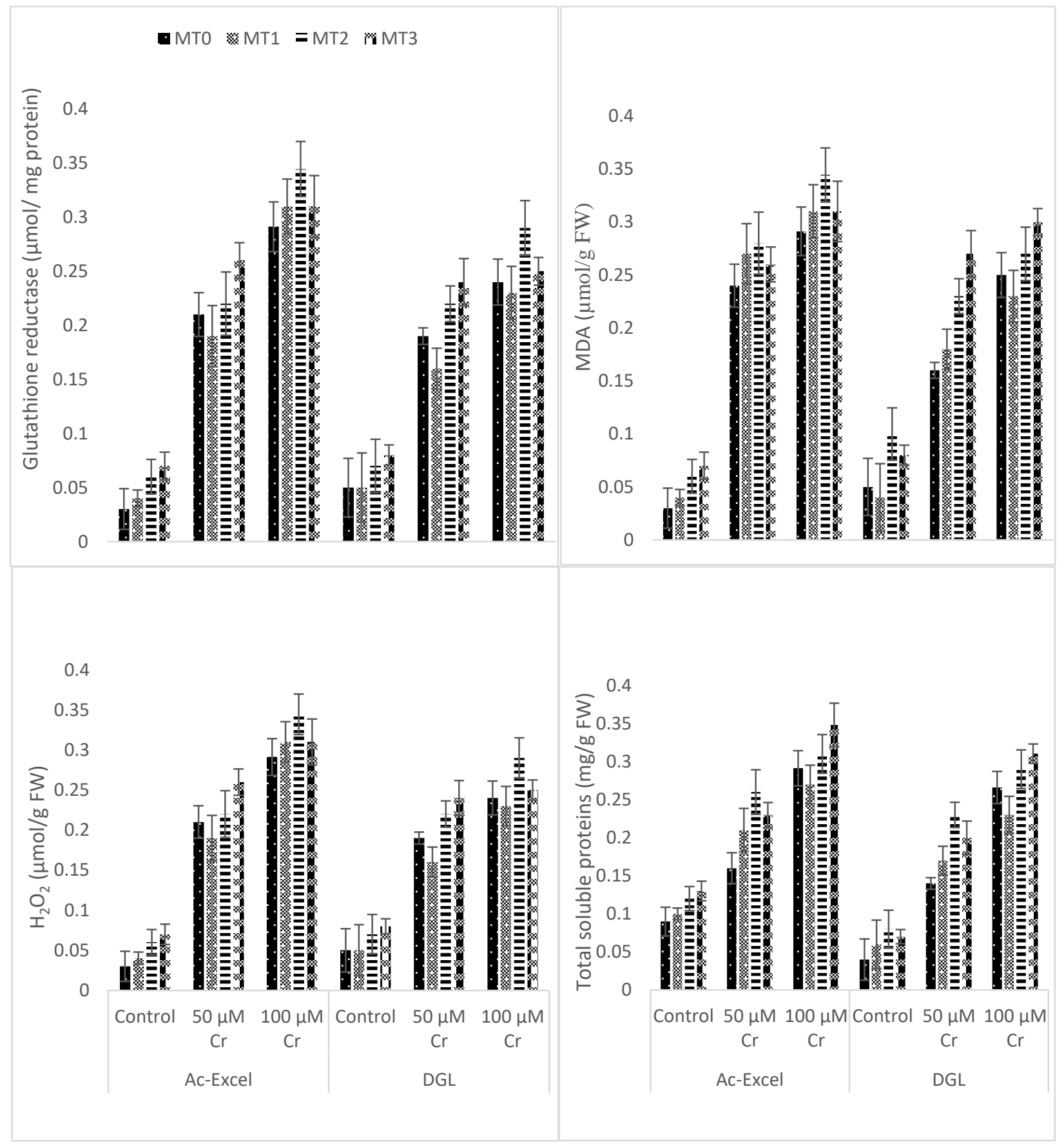

Fig.5: Melatonin induced Glutathione reductase, $\mathrm{MDA}, \mathrm{H}_{2} \mathrm{O}_{2}$, and Total Soluble Proteins of two Canola plants treated with chromium stress for two weeks. 


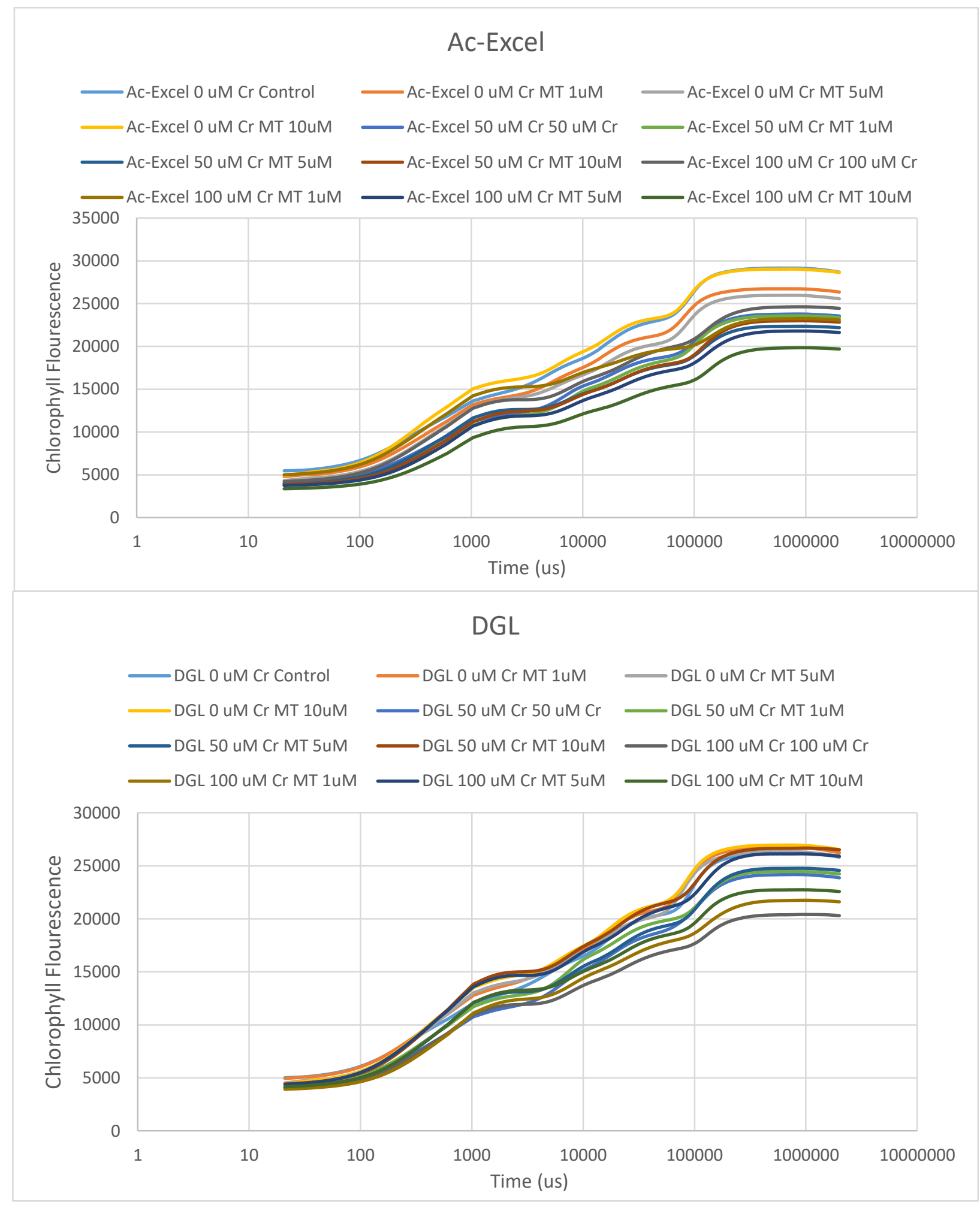

Fig.6: Melatonin induced Chlorophyll fluorescence variations of two Canola plants treated with chromium stress for two weeks. 
However, melatonin treated plants showed high antioxidants enzymes activity maximum activity was observed at $5 \mu \mathrm{M}$ concentration in chromium stress as well as in control conditions. This special increase in antioxidants were higher in Ac-Excell that of DGL cultivar.

Suggesting that Ac-Excell has higher potential and tolerance of metal toxicity by showing significantly more ROS contents i.e $\mathrm{H}_{2} \mathrm{O}_{2}$ and MDA and antioxidants enzymes such as superoxide dismutase (SOD), Peroxidase (POD) and Catalase (CAT), APX (Ascorbate peroxidase) and Glutathione reductase enzyme activity.

Chromium contents were observed significantly higher in chromium treated plants in both the canola plants, but cultivar DGL showed higher chromium accumulation that of Ac-Excell cultivar suggesting that hyper accumulation of chromium shows more damaging effect on plants physiology or overall plant growth that of Ac-Excell (Fig 2).

Foliar application of melatonin increased the amplitude of I-P curve in both genotypes of canola under control conditions, while in chromium stress amplitude is lowered in both the cultivars. Suggesting that melatonin may play vital role in increasing the electron pool carrier of photosystem I end, to be reduced from electron coming from PQ in both canola cultivars. Whereas I-P band that is measured as VIP $=[(\mathrm{Ft}-\mathrm{FI}) /(\mathrm{Fm}-\mathrm{FI})]$ indicates that chromium stress reduces the rate of constant value of Ac-Excell melatonin enhances the rate of constant value in Ac-Excell cultivar that of DGL. Chromium stress induced biophysical changes derived from chlorophyll fluorescence curve of canola cultivars explained as in radar plot as shown in (Fig.6).

However, improved values of $\mathrm{Fv} / \mathrm{Fo}$ and $\mathrm{Fm} / \mathrm{Fo}$ because of melatonin treatment was observed more in AcExcell under chromium treated that of non-treated plants. While increased values of Mo (primary photochemistry values) in Ac-Excell cultivar was observed to be improved in foliar application of melatonin that of chromium treated plants of canola shown in (Fig.6). Similarly, total Area (PQ pool), redox state of multiple PQ turnover $(\mathrm{Sm})$ and $\mathrm{Q}_{\mathrm{A}}$ redox turnover until $\mathrm{Fm}$ actually ( $\mathrm{N}$ values) was observed to be decreased in DGL only and melatonin application did not significantly affect the biophysical parameters as shown in (Fig.6). The derived fluxes of specific energy including ABS/RC (absorbance flux per reaction center), TRo/RC (trapped energy flux per reaction center), ETo/RC (electron transport flux per reaction center) and $\mathrm{DIo} / \mathrm{RC}$ dissipation energy flux per reaction center all of these fully reduced in chromium stressed plants of both cultivars and melatonin treatment induced improved OJIP transients in cultivar AcExcel cultivar then DGL this rapid electron transfer (reduction) rate becomes faster due to chromium toxicity, because of inactive reaction centers that of control plants.

In this regard our results suggested that exogenously applied melatonin under chromium stress have higher capacity to convert light energy to chemical energy which can be used to further $\mathrm{CO}_{2}$ to carbohydrates. Conversion of light energy into chemical energy was observed to be higher in cultivar Ac-Excell then DGL.

\section{DISCUSSION}

To alleviate the chromium stress induced reduction of canola cultivars, foliar application of melatonin is considered to be one of most affective strategy (Farouk and Al-Amri, 2019) and it has been confirmed in this study. Considerably, exogenously applied melatonin in addition to endogenously melatonin increases chromium tolerance and plants antioxidants defense capacity at significant level. We supposed that melatonin induced chromium tolerance and antioxidant defense system (ROS scavenging mechanism) by production of phyto-chelatins and compartmentalization of chromium in cell wall and vacuole plays a key role in chromium tolerance for canola plants (Roychoudhury et al., 2012).Similarly in the following study melatonin induced increased SOD,POD,CAT,APX and GR activity, which might modulates plants antioxidants activity by inducing ROS scavenging activity (lowering oxidative stress) against chromium stress (Fig 4,5).As melatonin treatment can decrease chlorophyll degradation, increased photosynthesis, antioxidants ability and drought tolerance cucumber seedlings (Zhang et al., 2013). It is assumed that melatonin induced photosynthetic ability in plants is because of some unusual bio-stimulating pathway by modulating photosystem II efficiency in certain light and dark conditions (Zhao et al., 2019).

Inside plants metal toxicity can be reduced by their reactions with metal ligands such as proteins, polysaccharides and organic acids (Andresen et al., 2018) until ratio of non-chelated metallic ions changed into metabolic organelles such as nucleus, chloroplast and mitochondria. These freely available metallic ions causes severe damage to these cellular organelles. Several previous studies suggested that metallic ions sequestration in root 
cortex and endodermis occurs because of decrease in transportation of metallic ions (acts as ultimately effective barrier) from root to shoot of plants (Song et al., 2017). In our study exogenously applied melatonin treated plants showed decreased transportation of chromium contents in cell wall and vacuole consequently reducing the chromium toxicity suggesting that melatonin acts as barrier by reducing transportation of chromium in 50 and $100 \mu$ Mchromium treated canola plants. Metallic ions (chromium ions) immobilization assumed to be co-related by melatonin induced biosynthesis of thiol compounds.

Metallic ions competes with mineral nutrients for the same transport system from root to shoot resulting ionic imbalance and disturbed plasma membrane stability (Nazar et al., 2012). $\mathrm{H}^{+}$-ATPase of plasma membrane that are responsible for the translocation of organic compound and ions across the plasma membrane (Gévaudant et al., 2007).Possibly melatonin improves this transportation of $\mathrm{H}^{+}$-ATPase by its conversion into 5-methoxytryptamine that stimulates $\mathrm{H}^{+}$ATPase activity in addition protects plasma membrane by reducing reactive oxygen species generation and enhancing antioxidants enzymes activity(Jiang \& Zhang, 2003).

Accordingly, in our study improved membrane stability, ions transportation and chromium tolerance in melatonin treated canola plants might be due to improved $\mathrm{H}^{+}$-ATPase activity in chromium treated plants.

Chromium toxicity affects plant photosynthesis process at very large scale, whereas Fv/Fm usually acts as key indicator of plant photosynthesis ability of plant. Generally $\mathrm{Fv} / \mathrm{Fm}$ always verified as a result of different pigment concentration and cell structure and can be affected by several environmental factors i.e light, nutrients, temperature and certain chemicals that alters the PSII efficiency ( $\mathrm{Li}$ et al., 2019). Several studies explained that chromium toxicity alters the structure and function of reaction centers and effects electron transport system which consequently reduces the $\mathrm{Fv} / \mathrm{Fm}$. Furthermore our results suggested that chromium toxicity significantly alters the PSII efficiency. Melatonin application in chromium stress prevents pigment degradation that helps in improving the overall photosynthetic process. Plants exposed to metals in root region causes inhibition of growth by producing reactive oxygen species that ultimately leads to plants death (Mizushima et al., 2019).

In such conditions plant increases the endogenous melatonin biosynthesis to cope up the metal toxicity as pea plants alleviates the copper stress (Ren et al., 2019). Several studies focused on the phytoremediation ability of plants by exogenous application of melatonin exposed to metal stress by enhancing root growth, antioxidant activity, photosynthesis, by organic acid anion exudation, by reducing metal contents, by increasing antioxidants related gene expression (Arnao and Hernández-Ruiz, 2019; Zhang et al., 2019) and by reactivating the micro RNA mediated redox homoeostasis in different crops (Wang et al., 2019). Similarly, exogenous application of melatonin with 150 $\mu \mathrm{mol} / \mathrm{L}$ for eggplant was considered as best concentration for plant against cadmium stress. Melatonin enables plants in cadmium sequestration and transformation from cytosol to vacuole and cell wall (Lv et al., 2019). In addition melatonin application mitigates heavy metal stimulated oxidative stress by enhancing enzymatic and non-enzymatic antioxidant activity (Kaya et al., 2019). Whereas melatonin has amazing efficiently to up regulate the ion channel expression against cadmium stress. However, melatonin with $1 \mu \mathrm{mol}$ concentration treatment alleviates the boron toxicity by improving nutrients uptake efficiency, photosynthetic activity, carbohydrates accumulation, antioxidant defense system and reduces reactive oxygen species (ROS) and membrane permeability in winter wheat (Qiao et al., 2019).

However, melatonin induced improvement in photosynthetic efficiency of Ac-Excel cultivar that of DGL is because of its genetic potential but its effect on the exact site of photosynthetic apparatus is still unclear. In a semiquantitative observation of melatonin treatment with and without chromium stress on different parts of photosynthetic apparatus of canola cultivars, whole OJIP normalized transients of chromium stressed and non-stressed plants were measured. All the transient data of canola plants of present study explained that primary photochemistry fluorescence and photo electrochemical quenching at O-J and J-I step reduced due chromium stress in both canola cultivars whereas melatonin application increased the photosynthetic activity by compensating reduction rate at PSI and electron acceptor at step I-P site in Canola cultivars especially in AcExcel than DGL. In addition Fo normalized transient and relative variable fluorescence transients of $\mathrm{Fo}$ and $\mathrm{Fm}$ verified our results (Fig.6), for detailed analysis whole difference of kinetics at each step from OJ-JI-IP was performed (Fig.3, 4, 5). Low fluorescence values in L-band in chromium stress conditions showed that loss of energetic connectivity to some extent due to chromium toxicity. 
Similarly, K-band showed both canola cultivars showed maximum ability of resistance for donor and acceptor sides of PSII imbalance at $1000 \mu$ s against chromium stress. While, an increase in K-band peaks from 1000-2000 $\mu$ s showed reduced oxygen evolving complex (OEC) performance because of electron flow imbalance from (OEC) to reaction center at acceptor site of PSII in chromium stress. However, at 1000-2000 $\mu$ s decreased fluorescence curve at K-band under melatonin treatment against chromium stress (Fig.4, 5) suggested that both the canola cultivars showed maximum resistance to electron imbalance at donor and acceptor sides of PSII. Similarly, at O-I step (describes redox properties of PQ poll) decreased/negative fluorescence $(\Delta \mathrm{VOI})$ curve described the involvement of melatonin in maintaining the maximum PQ reduction rate in both cultivars against chromium stress.

Meanwhile, fluorescence curve at I-P step that indicates the electron transfer rate from $\mathrm{PQH}_{2}$ to electron accepter end of PSI, melatonin treated plants showed positive increased in fluorescence transient values at I-P step in chromium stress, while decreased in chromium treated plants suggesting that exogenous melatonin application enhanced PQ redox rate ultimately lowering the chromium stress and increased PQ pool size in both the canola cultivars. Decreased fluorescence transient curve at I-P phase eventually happens because of sharp decline of leaf water status in chromium stress that might reaches to maximum tolerance level of pants. Chlorophyll fluorescence transients and their different ratios at each step of OJIP considered as key indicators for PSII efficiency evaluation.

Chromium stress significantly reduces Fo (minimum fluorescence level) that eventually increases energy excitation and transfer rate from antenna complex to reaction center ultimately leads to low Fo. However, melatonin treated plants also have reduced Fo values, resulting increase in electron transfer efficiency from antenna complex to PSII reaction center. While Fm (maximal fluorescence) values were also reduced in chromium stress that explains the reduction in electron transfer to PSII acceptor site, indicating induced changes in $\mathrm{Q}_{\mathrm{A}}$ reduction rate. Foliar application of melatonin enables the plants to maintain balance of plastoquinoneredox state by transferring electron to PSI. Melatonin treated plants showed reduction in $\mathrm{ABS} / \mathrm{RC}$ values suggested, increased size of antenna complex of active reaction centers. However, PI most sensitive parameter of OJIP indicates the conformational changes and confirms the vitality canola plants of PSII.
While exogenously applied melatonin in chromium stress increased the PI values and possible link between ETo/RC and $\log \mathrm{PI}_{\mathrm{ABS}}$ that suggests the utilization of PAR which reduces the $\mathrm{CO}_{2}$ into sugars in natural environmental conditions.

\section{CONCLUSION}

The melatonin induced difference observed between two canola cultivars suggests that cultivars have different metal tolerance capability in chromium stress. Chromium toxicity reduced the plant growth, chlorophyll contents and photosynthetic activity in both the cultivars but DGL showed greater effect indicating more sensitive as compared to AcExcel. Similarly, enzymatic antioxidant activities were increased in Ac-Excell cultivar suggesting the greater metal tolerance and photosynthetic response against chromium stress. To overcome these stressful conditions exogenous application of hormones as melatonin used in our study effectively can increase the plant growth, development and tolerance against certain environmental stress. There is need to focus on exogenous application of growth enhancing agents that enables plants especially agricultural crops to increase their yield and tolerance against toxic elements.

\section{REFERENCES}

[1] Aebi, H., 1984. Catalase in vitro, Methods in Enzymology. Elsevier, pp. 121-126.

[2] Ali, S., Farooq, M.H., Hussain, S., Yasmeen, T., Abbasi, G.H., Zhang, G., 2013d. Alleviation of chromium toxicity by hydrogen sulfide in barley. Environ. Toxicol. Chem. 32, 22342239.

[3] Andresen, E., E. Peiter and H. Küpper. 2018. Trace metal metabolism in plants. J. Exp. Bot., 69: 909-954.

[4] Arnon, D.I. 1949. Copper enzymes in isolated chloroplasts. Polyphenoloxidase in Beta vulgaris. Plant Physiol., 24: 1.

[5] Aparicio, J.D., Garcia-Velasco, N., Urionabarrenetxea, E., Soto, M., Álvarez, A., Polti, M.A., 2019. Evaluation of the effectiveness of a bioremediation process in experimental soils polluted with chromium and lindane. Ecotoxicology and Environmental Safety 181, 255-263.

[6] Arnao, M.B., Hernández-Ruiz, J., 2019. Melatonin as a chemical substance or as phytomelatonin rich-extracts for use as plant protector and/or biostimulant in accordance with EC legislation. Agronomy 9, 570.

[7] Arnon, D.I., 1949. Copper enzymes in isolated chloroplasts. Polyphenoloxidase in Beta vulgaris. Plant Physiology 24, 1.

[8] Bychkov, I., Kudryakova, N., Andreeva, A., Pojidaeva, E., Kusnetsov, V., 2019. Melatonin modifies the expression of the 
genes for nuclear-and plastid-encoded chloroplast proteins in detached Arabidopsis leaves exposed to photooxidative stress. Plant Physiology and Biochemistry 144, 404-412.

[9] Cheng, N., Ren, N., Gao, H., Lei, X., Zheng, J., Cao, W., 2013. Antioxidant and hepatoprotective effects of Schisandrachinensis pollen extract on CCl4-induced acute liver damage in mice. Food and Chemical Toxicology 55, 234240.

[10] Chen, J., Chen, J., Liu, Y., Zheng, Y., Zhu, Q., Han, G., Shen, J., 2019. Proton-Coupled Electron Transfer of Plastoquinone Redox Reactions in Photosystem II: A Pump-Probe Ultraviolet Resonance Raman Study. The journal of physical chemistry letters.

[11] Di, T., Zhao, L., Chen, H., Qian, W., Wang, P., Zhang, X., Xia, T., 2019. Transcriptomic and metabolic insights into the distinctive effects of exogenous melatonin and gibberellin on terpenoidsynthesis and plant hormone signal transduction pathway in Camellia sinensis. Journal of Agricultural and Food Chemistry 67, 4689-4699.

[12] Kodru, S., T. Malavath, E. Devadasu, S. Nellaepalli, A. Stirbet and R. Subramanyam. 2015. The slow S to M rise of chlorophyll a fluorescence reflects transition from state 2 to state 1 in the green alga Chlamydomonasreinhardtii. Photosynthesis Res., 125: 219-231.

[13] Farouk, S., Al-Amri, S., 2019. Ameliorative roles of melatonin and/or zeolite on chromium-induced leaf senescence in marjoram plants by activating antioxidant defense, osmolyte accumulation, and ultrastructural modification. Industrial Crops and Products 142, 111823.

[14] Franić, M., Galić, V., 2019. As, Cd, Cr, Cu, Hg: Physiological Implications and Toxicity in Plants, Plant Metallomics and Functional Omics. Springer, pp. 209-251.

[15] Ghori, N.-H., Ghori, T., Hayat, M., Imadi, S., Gul, A., Altay, V., Ozturk, M., 2019. Heavy metal stress and responses in plants. International journal of environmental science and technology 16, 1807-1828.

[16] Gévaudant, F., G. Duby, E. von Stedingk, R. Zhao, P. Morsomme and M. Boutry. 2007. Expression of a constitutively activated plasma membrane H+-ATPase alters plant development and increases salt tolerance. Plant Physiol., 144: 1763-1776.

[17] Gómez, R., Vicino, P., Carrillo, N., Lodeyro, A.F., 2019. Manipulation of oxidative stress responses as a strategy to generate stress-tolerant crops. From damage to signaling to tolerance. Critical Reviews in Biotechnology 39, 693-708.

[18] Griffith, O.W., 1980. Determination of glutathione and glutathione disulfide using glutathione reductase and 2vinylpyridine. Analytical Biochemistry 106, 207-212.

[19] Hodges, D.M., DeLong, J.M., Forney, C.F., Prange, R.K., 1999. Improving the thiobarbituric acid-reactive-substances assay for estimating lipid peroxidation in plant tissues containing anthocyanin and other interfering compounds. Planta 207, 604-611.
[20] Nakano, Y., Asada, K., 1981. Hydrogen peroxide is scavenged by ascorbate-specific peroxidase in spinach chloroplasts. Plant and Cell Physiology 22, 867-880.

[21] Rao, M.V., Paliyath, G., Ormrod, D.P., 1996. Ultraviolet-Band ozone-induced biochemical changes in antioxidant enzymes of Arabidopsis thaliana. Plant Physiology 110, 125136.

[22] Ifon, B.E., Togbé, A.C.F., Tometin, L.A.S., Suanon, F., Yessoufou, A., 2019. Metal-Contaminated Soil Remediation: Phytoremediation, Chemical Leaching and Electrochemical Remediation, Metals in Soil-Contamination and Remediation. IntechOpen.

[23] Kaya, C., Okant, M., Ugurlar, F., Alyemeni, M.N., Ashraf, M., Ahmad, P., 2019. Melatonin-mediated nitric oxide improves tolerance to cadmium toxicity by reducing oxidative stress in wheat plants. Chemosphere 225, 627-638.

[24] Kabiri, R.; Hatami, A.; Oloumi, H.; Naghizadeh, M.; Nasibi, F.; Tahmasebi, Z. Foliar application of melatonin induces tolerance to drought stress in Moldavian balm plants ( Dracocephalummoldavica ) through regulating the antioxidant system. Folia Hort. 2018, 30, 155-167.

[25] Kotecha, M., Chaudhary, S., Marwa, N., Deeba, F., Pandey, V., Prasad, V., 2019. Metals, Crops and Agricultural Productivity: Impact of Metals on Crop Loss, Plant-Metal Interactions. Springer, pp. 191-216.

[26] Küpper, H., Benedikty, Z., Morina, F., Andresen, E., Mishra, A., Trtilek, M., 2019. Analysis of OJIP Chlorophyll Fluorescence Kinetics and QA Reoxidation Kinetics by Direct Fast Imaging. Plant Physiology 179, 369-381.

[27] Kodru, S., T. Malavath, E. Devadasu, S. Nellaepalli, A. Stirbet and R. Subramanyam. 2015. The slow $\mathrm{S}$ to $\mathrm{M}$ rise of chlorophyll a fluorescence reflects transition from state 2 to state 1 in the green alga Chlamydomonasreinhardtii. Photosynthesis Res., 125: 219-231.

[28] Li, L., Long, M., Islam, F., Farooq, M.A., Wang, J., Mwamba, T.M., Shou, J., Zhou, W., 2019. Synergistic effects of chromium and copper on photosynthetic inhibition, subcellular distribution, and related gene expression in Brassica napus cultivars. Environmental Science and Pollution Research 26, 11827-11845.

[29] Lv, X., Fang, Y., Zhang, L., Zhang, W., Xu, L., Han, J., Zhang, X., Zhang, X., Xue, D., 2019. The Effects of melatonin on growth, physiology and gene expression in rice seedlings under Cadmium stress. Phyton, International Journal of Experimental Botany 88, 91-100.

[30] Martinez, V.; Nieves-cordones, M.; Lopez-delacalle, M.; Rodenas, R.; Mestre, T.C.; Garcia-sanchez, F.; Rubio, F.; Nortes, P.A.; Mittler, R.; Rivero, R.M. Tolerance to stress combination in tomato plants: New insights in the protective role of melatonin. Molecules 2018, 23, 535.

[31] Meng, H.B., Hua, S.J., Shamsi, I.H., Jilani, G., Li, Y.L., Jiang, L.X., 2009. Cadmium induced stress on the seed germination and seedling growth of Brassica napus L., and its alleviation 
through exogenous plant growth regulators. Plant Growth Regul. 58, 47-59

[32] Mizushima, M., Ferreira, B., França, M., Almeida, A.A., Cortez, P., Silva, J., Jesus, R., Prasad, M., Mangabeira, P., 2019. Ultrastructural and metabolic disorders induced by short-term cadmium exposure in Avicenniaschaueriana plants and its excretion through leaf salt glands. Plant Biology 21, 844-853.

[33] Nazar, R., N. Iqbal, A. Masood, M.I.R. Khan, S. Syeed and N.A. Khan. 2012. Cadmium toxicity in plants and role of mineral nutrients in its alleviation.

[34] Oves, M., Saghir Khan, M., Huda Qari, A., NadeenFelemban, M., Almeelbi, T., 2016. Heavy metals: biological importance and detoxification strategies. Journal of Bioremediation and Biodegradation 7, 1-15.

[35] Qiao, Y., Yin, L., Wang, B., Ke, Q., Deng, X., Wang, S., 2019. Melatonin promotes plant growth by increasing nitrogen uptake and assimilation under nitrogen deficient condition in winter wheat. Plant Physiology and Biochemistry 139, 342349.

[36] Roychoudhury, A., S. Pradhan, B. Chaudhuri and K. Das. 2012. 11 Phytoremediation of Toxic Metals and the Involvement of Brassica Species.

[37] Roychoudhury, A., S. Pradhan, B. Chaudhuri and K. Das. 2012. 11 Phytoremediation of Toxic Metals and the Involvement of Brassica Species.

[38] Rajendran, M., An, W.-h., Li, W.-c., Perumal, V., Wu, C., Sahi, S.V., Sarkar, S.K., 2019. Chromium detoxification mechanism induced growth and antioxidant responses in vetiver (Chrysopogonzizanioides (L.) Roberty). Journal of Central South University 26, 489-500.

[39] Ren, S., Rutto, L., Katuuramu, D., 2019. Melatonin acts synergistically with auxin to promote lateral root development through fine tuning auxin transport in Arabidopsis thaliana. PloS one 14.

[40] Saglam, A., Chaerle, L., Van Der Straeten, D., Valcke, R., 2019. Promising Monitoring Techniques for Plant Science: Thermal and Chlorophyll Fluorescence Imaging. Photosynthesis, Productivity and Environmental Stress, 241266.

[41] Souri, Z., Cardoso, A.A., da-Silva, C.J., de Oliveira, L.M., Dari, B., Sihi, D., Karimi, N., 2019. Heavy Metals and Photosynthesis: Recent Developments. Photosynthesis, Productivity and Environmental Stress, 107-134.

[42] Song, Y., L. Jin and X. Wang. 2017. Cadmium absorption and transportation pathways in plants. Int. J. Phytoremediation, 19: 133-141.

[43] Wang, L.Y.; Liu, J.L.;Wang,W.X.; Sun, Y. Exogenous melatonin improves growth and photosynthetic capacity of cucumbers under salinity-induced stress. Photosynthetica2015, $53,1-10$.

[44] Wang, M., Duan, S., Zhou, Z., Chen, S., Wang, D., 2019. Foliar spraying of melatonin confers cadmium tolerance in
Nicotianatabacum L. Ecotoxicology and Environmental Safety 170, 68-76.

[45] Zhou, B., Wang, J., Guo, Z., Tan, H., Zhu, X., 2006. A simple colorimetric method for determination of hydrogen peroxide in plant tissues. Plant growth regulation 49, 113-118.

[46] Zhang, J., Li, D., Wei, J., Ma, W., Kong, X., Rengel, Z., Chen, Q., 2019. Melatonin alleviates aluminum-induced root growth inhibition by interfering with nitric oxide production in Arabidopsis. Environmental and Experimental Botany 161, 157-165.

[47] Zhang, N., B. Zhao, H.J. Zhang, S. Weeda, C. Yang, Z.C. Yang, S. Ren and Y.D. Guo. 2013. Melatonin promotes water-stress tolerance, lateral root formation, and seed germination in cucumber (Cucumissativus L.). J. Pineal Res., 54: 15-23.

[48] Zhao, D., Y. Yu, Y. Shen, Q. Liu, Z. Zhao, R. Sharma and R.J. Reiter. 2019. Melatonin Synthesis and Function: Evolutionary History in Animals and Plants. Frontiers in endocrinology, 10: 249-249.

[49] Zhou, B., J. Wang, Z. Guo, H. Tan and X. Zhu. 2006. A simple colorimetric method for determination of hydrogen peroxide in plant tissues. Plant Growth Regulation, 49: 113-118. 